\title{
Psychological factors and outcomes of coronary surgery
}

\author{
Leo A. Bokeria ${ }^{\text {a }}$, Yuri P. Zinchenko ${ }^{\mathrm{b}}$, Maria G. Kiseleva ${ }^{\mathrm{a}}$ \\ ${ }^{a}$ Bakoulev Center for Cardiovascular Surgery of the Russian Academy of Medical Science, \\ Moscow, Russia \\ ${ }^{b}$ Lomonosov Moscow State University, Moscow, Russia
}

\begin{abstract}
Although heart surgery is one of the most effective methods in treating cardiovascular diseases, more than $50 \%$ of patients have problems in personal, social, professional adaptation after surgery (Pogosova, 1996).

According to recent studies, psychological factors contribute significantly to negative outcomes of coronary surgery. The main factors are: depression, anxiety, personal factors and character traits, social isolation, and chronic life stress (Blumental, 2003; Connerney, 2010; Contrada, 2008; Cserep, 2010, Gallagher, 2007; Hoyer, 2008; Pigney-Demaria, 2003; Rozancki, 1999; Rymaszewska, 2003; Viars, 2009, Zaitsev, 1997).

The aim of the article is to describe the association between psychological factors and the outcomes of coronary surgery. We have studied how the patient's attitude towards forthcoming open heart surgery is associated with the outcomes.

We have picked out four types of attitude towards forthcoming heart surgery: 1) pessimistic (no belief in recovery, surgery is threatening, damaging), 2) indifferent (no belief in recovery, surgery will not change anything),

3) optimistic but not realistic (exaggerated expectations, belief in full recovery), 4) optimistic and realistic (adequate expectations, belief in improvement).

The study has shown that patients with optimistic-realistic attitudes towards forthcoming heart surgery have better outcomes, better emotional status, and shorter stays in hospital.
\end{abstract}

Key words: heart surgery, nocebo effect, depression, anxiety, postoperative period.

\section{Introduction}

Recent studies provide clear and convincing evidence that such psychological factors as depression, anxiety, personality factors, social isolation, and chronic life stress contribute greatly to the pathogenesis and expression of coronary artery disease (CAD) (Rosancki, Blumenthal, Kaplan, 1999, Sokolova, Nikolaeva, 1995). The pathophysiological mechanism by which these factors promote CAD includes 1) 
behavioral and 2) direct pathophysiological effects (Rosancki, Blumenthal, Kaplan, 1999). Since there is plenty of information on this part of the problem, we will turn our attention straight to the situation of open heart surgery.

By and large, there are several treatment choices to consider in a patient with significant CAD disease: medication, bypass surgery, angioplasty, or combination of these (Laurence, 2002). If the treatment were simple and without potentially adverse effects, the decision on treatment would be simple. But the reality is more complicated. Bypass surgery is by far the most traumatic, as it involves surgery and anesthesia, a long recovery period, and potential complications (Bokeria, 2010, Laurence, 2002). It can fail, prove ineffective, or even result in death. Uncertainty is the hardest part of experiencing illness.

Although the cardiologist decides on the best treatment in every situation, the patient takes his share of responsibility in agreeing to the surgery. Even when the best treatment choice is obvious for the physician, it can be unacceptable to the patient, who fears hospitalization, pain, or has a friend whose outcome from similar treatment was poor. In such a situation, the biopsychosocial view of illness and the role of the psychologist who can help identify the problem is very important.

The situation of open heart surgery consists of a patient's subjective perception of what medics do and say, a prognosis of the surgery outcome, and many other factors which take on a secondary psychosemantic meaning. Inadequate implicit concepts of forthcoming surgery can produce respective somatic sensations and, on the contrary, real somatic sensations can be wrongly identified by the patient (Thostov, 2002). Models of negative surgery outcomes can cause a negative placebo affect (nocebo effect). A nocebo effect is an ill effect caused by the suggestion or belief that something is harmful.

When a patient faces the necessity of open heart surgery (coronary artery bypass for CAD patients) he finds himself in a terrifying situation with an unknown outcome. The threat for his body image, life risk, pain, and helplessness stir up many feelings.

Recent studies show that depression and anxiety symptoms common for CAD patients worsen the outcomes of cardiac surgery (Allen, Becker, 1990; Appels, Mulder, 1988; Atrinian, 1991; Berron, 1986; Blumental, 1988, 2003; Connerney, 2010; Contrada, 2008; Cserep, 2010, Gallagher, 2007; Hoyer, 2008; Pigney-Demaria, 2003; Rozancki, 1999; Rymaszewska, 2003; Viars, 2009, Zaitsev, 1997). In such a situation, psychological support is very necessary.

Patients stay in hospital for only a few days before the surgery, so there is not much time for deep psychological intervention. This means that identifying the main targets for psychological help is very important.

We suggest that the negative attitude of patients towards forthcoming open heart surgery is associated with the adverse postsurgical period. The type of attitude towards forthcoming open heart surgery determines illness behavior, compliance, and coping strategies. Assistance in modeling adequate expectations from surgical treatment should be one of the targets of psychological maintenance in the perioperative period. 


\section{Method}

120 patients ( $44 \%$ female) with CAD, scheduled for open heart surgery, volunteered for the study (the study group). The mean age was $48 \pm 13$. NYHA class - II-III.

The control group consisted of 35 people ( $45 \%$ females) without somatic and mental disorders.

Patients from the study group were interviewed and asked to fill in questionnaires the day before heart surgery, and one week afterwards.

The Center for Epidemiologic Studies Depression Scale (CES-D) was used to measure depression rate; State-Trait Anxiety Inventory (STAI) was used for anxiety rate.

The attitude towards forthcoming heart surgery was picked up after the analysis of data received from a specially designed clinical interview, the Semantic differential scale, the Dembo-Rubinshtein self-rating method (scales: health, happiness, life satisfaction, emotional comfort, self confidence, treatment satisfaction), and the Etkind Color Test of attitudes (50 words describing the situation of open heart surgery and different fillings).

The study of the patient's history was used to estimate the outcome (number of postoperative complications (2), and calculate number of days spent in the hospital.

We used standard statistics methods (t-test, Mann-Whitney U, Spearman's rho, Pearson Chi-square) for data analysis.

The research took place in the Department of Surgical Treatment for Interactive Pathology at the Bakoulev Center for Cardiovascular Surgery of the Russian Academy of Medical Science, Moscow, Russia.

\section{Results}

The level of depression, state, and trait anxiety was significantly higher in the study group than in the control group $(\mathrm{p}<0,05)$. The level of self-rated emotional comfort was significantly lower in the study group.

In the study group, $7.1 \%$ of patients had a high level (more then 25 points by CES-D) and 27\% a heightened level (more then 19 points by CES-D) of depression symptomatology.

In the study group, $54.8 \%$ of patients had high level (more then 46 points by STAI) and $27 \%$ a heightened level (more then 31 points by STAI) of state anxiety.

Correlation analysis of the relationship between depression, state anxiety levels, and the number of postsurgical complications determined a significant positive correlation $(p=0,000)$. The higher level of depression correlated with more complications, and the same correlation was true for the relationship between the state anxiety level and the number of postsurgical complications.

Correlation analysis of the relationship between depression, state anxiety levels and the number of days spent in the hospital determined a significant positive correlation $(p=0,000)$. The higher level of depression correlated with more days spent in the hospital, and the same correlation was true for the relationship between the state anxiety level and the number of days spent in the hospital. 
A significant negative correlation was detected between the level of self-rated emotional comfort and the number of postsurgical complications. A significant negative correlation was detected between the level of self-rated emotional comfort and the number of days spent in the hospital after surgery. The lower mark the patients gave to their emotional comfort before surgery, the more complications they had after surgery, and the more days they spent in the hospital after surgery.

Analysis of social and demographic data determined the following. Age and educational level did not significantly influence the levels of depression, state and trait anxiety, self-rated life satisfaction, happiness, or emotional comfort $(\mathrm{p}<0,05)$.

On the contrary, the absence of a constant job has a significant influence on the levels of depression, trait anxiety, self-rated life satisfaction, happiness, and emotional comfort. Thus, non-working patients had significantly higher levels of depression, trait anxiety, and significantly lower levels of self-rated life satisfaction, happiness, and emotional comfort $(\mathrm{p}<0,05)$ than working patients.

Following the analysis of data received from the Semantic differential scale, Dembo-Rubinshtein self-rating method, and the Etkind Color Test of attitudes, we have picked out four types of attitude towards forthcoming open heart surgery: 1) pessimistic (no belief in recovery, surgery is threatening, damaging), 2) indifferent (no belief in recovery, surgery will not change anything),

3) optimistic, but not realistic (exaggerated expectations, belief in full recovery), 4) optimistic - realistic (adequate expectations, belief in improvement).

In the study group $15 \%$ had pessimistic, $20 \%$ had indifferent, $35 \%$ had optimistic but not realistic, and 30\% had optimistic-realistic attitudes towards forthcoming open heart surgery.

Sex distribution does not significantly differ in the dedicated groups, except that the group with indifferent patients where $96 \%$ were male.

The educational level does not significantly differ in the dedicated groups, except the group with indifferent patients, where $78,6 \%$ of patients did not have a higher education.

$20.8 \%$ of pessimistic patients had constant jobs, $25 \%$ of indifferent patients had constant jobs, $65.7 \%$ of optimistic but not realistic patients had constant jobs, and $52,9 \%$ of optimistic-realistic patients had constant jobs.

Age, marriage status, and length of illness do not significantly differ in the dedicated groups.

Patients with a pessimistic attitude concentrate on the negative aspects of forthcoming open heart surgery. They have a high level of fear before the surgery, especially a fear of death. Their emotions vary from fright and despair to anger and hostility. They are prone to speaking about the forthcoming treatment in a binary manner. They feel a total loss of control over the situation. Such patients have many somatic complaints, and problems in coping with pain.

Patients with pessimistic attitudes have the highest rates of depression (Table 1), and state and trait anxiety. They have high emotional discomfort during the perioperative period. The prevailing associations with "surgery" are: despair, misfortune, and death (The Etkind Color Test of attitudes). 
Patients with indifferent attitudes think there is no sense in the forthcoming open heart surgery. They demonstrate that they do not control their lives, and that nothing depends on them. They usually say that their illness controls their life.

Such patients do not speak much, have a poor variety of emotions, and are not motivated for the treatment. They feel comfortable in hospital, and prefer to stay there as long as possible.

Indifferent patients are very close in their rates of depression to pessimistic patients, but do not feel as much emotional discomfort as pessimistic patients do. The prevailing associations with "surgery" are guilt and sorrow (The Etkind Color Test of attitudes).

Patients with optimistic but not realistic attitudes endow the situation of the forthcoming open heart surgery with unrealistic characteristics. Surgeons seem to them omnipotent and able to solve all the patient's problems. They expect total recovery and do not focus their attention on probable complications. They deny any fear or anxiety before the surgery.

During the first days after surgery they appear depressed and confused because their expectations were proved wrong. Nevertheless, most of them return to their good mood very soon.

Table 1. Emotional status (ES) and different types of attitude towards forthcoming heart surgery (ATHS).

\begin{tabular}{|c|c|c|c|c|c|}
\hline $\begin{array}{r}\text { Types of } \\
\text { ATHS }\end{array}$ & $\begin{array}{l}\text { Pessimistic } \\
\quad(p 1)\end{array}$ & $\begin{array}{l}\text { Optimistic not } \\
\text { realistic (p2) }\end{array}$ & $\begin{array}{l}\text { Indifferent } \\
\quad(\mathrm{p} 3)\end{array}$ & $\begin{array}{c}\text { Optimistic } \\
\text { Realistic (p4) }\end{array}$ & T-test Syg. \\
\hline $\begin{array}{l}\text { Depression } \\
\text { rate before } \\
\text { surgery }\end{array}$ & $19.4 \pm 8.9$ & $7.4 \pm 3.1$ & $16.8 \pm 5.3$ & $9.3 \pm 3.6$ & $\begin{array}{l}\text { p1-p2 }=0.000 \\
\text { p1-p4 }=0.000 \\
\text { p2-p3 }=0.000 \\
\text { p2-p4 }=0.021\end{array}$ \\
\hline $\begin{array}{l}\text { Depression } \\
\text { rate after } \\
\text { surgery }\end{array}$ & $22.3 \pm 8.4$ & $10.3 \pm 4.9$ & $21.0 \pm 5.8$ & $9.9 \pm 3.4$ & $\begin{array}{l}\text { p1-p2 }=0.000 \\
\text { p2-p3 }=0.000 \\
\text { p1-p4 }=0.000 \\
\text { p3-p4 }=0.000\end{array}$ \\
\hline $\begin{array}{l}\text { Trait anxiety } \\
\text { rate }\end{array}$ & $52.7 \pm 4.9$ & $41.8 \pm 7.6$ & $47.0 \pm 4.2$ & $44.9 \pm 6.3$ & $\begin{array}{l}\text { p1-p2 }=0.000 \\
\text { p1-p3 }=0.000 \\
\text { p1-p4 }=0.000 \\
\text { p2-p3 }=0.002\end{array}$ \\
\hline $\begin{array}{l}\text { State anxiety } \\
\text { rait }\end{array}$ & $50.9 \pm 5.1$ & $42.5 \pm 7.8$ & $45.6 \pm 5.7$ & $43.9 \pm 6.3$ & $\begin{array}{l}\text { p1-p2 }=0.000 \\
\text { p1-p3 }=0.001 \\
\text { p1-p4 }=0.000\end{array}$ \\
\hline $\begin{array}{l}\text { Self-rated } \\
\text { emotional } \\
\text { comfort be- } \\
\text { fore surgery }\end{array}$ & $34.8 \pm 21.3$ & $74.2 \pm 18.3$ & $43.2 \pm 22.1$ & $56.2 \pm 11.8$ & $\begin{array}{l}\text { p1-p2 }=0.000 \\
\text { p1-p4 }=0.000 \\
\text { p2-p3 }=0.000 \\
\text { p2-p4 }=0.000 \\
\text { p3-p4 }=0.008\end{array}$ \\
\hline $\begin{array}{l}\text { Self-rated } \\
\text { emotional } \\
\text { comfort after } \\
\text { surgery }\end{array}$ & $48.9 \pm 21.0$ & $70.9 \pm 17.3$ & $43.6 \pm 13.8$ & $78.7 \pm 13.4$ & $\begin{array}{l}\text { p1-p2 }=0.000 \\
\text { p1-p4 }=0.012 \\
\text { p2-p3 }=0.000 \\
\text { p3-p4 }=0.000\end{array}$ \\
\hline
\end{tabular}


The prevailing associations with "surgery" are: care, happiness, love (The Etkind Color Test of attitudes).

Optimistic but not realistic patients have the lowest rates of depression ( $\mathrm{Ta}$ ble 1), and state and trait anxiety. They have the lowest emotional discomfort during the perioperative period. They declare that they are really happy to be in hospital. After surgery they have the biggest rise in depression rates, though it is still low.

Patients with optimistic-realistic attitudes towards forthcoming heart surgery admit their worries, and can bear reasonable fear before open heart surgery.

They understand that the surgery is a necessity, they share responsibility for choosing this form of treatment, and understand what they can do to help the situation.

They plan their lives according to the state of their health. They have a variety of interests and hobbies in their lives.

Optimistic-realistic patients have low rates of depression (Table 1), and state and trait anxiety. They have emotional discomfort coincidental with the situation.

The prevailing associations with "surgery" are: chance, worry, pride (The Etkind Color Test of attitudes).

So patients with pessimistic and indifferent attitudes towards forthcoming heart surgery have much more emotional discomfort during the perioperative period. They also have an adverse postoperative period (complicated and long), and are not satisfied with the treatment (Table 2).

Patients with pessimistic attitudes towards forthcoming heart surgery had 1.68 \pm 0.79 complications, and stayed in hospital for $23.71 \pm 10.0$ days after surgery. They were only $58.72 \pm 24.11 \%$ satisfied with the treatment.

Patients with indifferent attitudes towards forthcoming heart surgery had $1.77 \pm 0.81$ complications, and stayed in hospital for $18.53 \pm 5.3$ days after surgery. They were only $62.11 \pm 22.28 \%$ satisfied with the treatment.

Table 2. The attitude towards forthcoming heart surgery (ATHS) and the surgery outcomes.

\begin{tabular}{lccc}
\hline \multicolumn{1}{c}{ ATHS } & $\begin{array}{c}\text { Number of postsurgical } \\
\text { Complications }\end{array}$ & $\begin{array}{c}\text { Number of days stayed } \\
\text { in hospital after surgery }\end{array}$ & $\begin{array}{c}\text { Satisfaction with } \\
\text { the treatment }\end{array}$ \\
\hline Pessimistic & $1.68 \pm 0.79$ & $23.71 \pm 10.0$ & $58.72 \pm 24.11$ \\
Indifferent & $1.77 \pm 0.81$ & $18.53 \pm 5.3$ & $62.11 \pm 22.28$ \\
$\begin{array}{l}\text { Optimistic not } \\
\text { Realistic }\end{array}$ & $0.91 \pm 0.58$ & $16.01 \pm 6.9$ & $84.82 \pm 17.71$ \\
$\begin{array}{l}\text { Optimistic } \\
\text { Realistic }\end{array}$ & $0.2 \pm 0.5$ & $10.0 \pm 0.1$ & $75.3 \pm 14.0$ \\
\hline
\end{tabular}

Patients with pessimistic attitudes towards forthcoming heart surgery had $0.91 \pm 0.58$ complications and stayed in hospital for $16.01 \pm 6.9$ days after surgery. They were $84.82 \pm 17.71 \%$ satisfied with the treatment.

Patients with pessimistic attitudes towards forthcoming heart surgery had 0.2 \pm 0.5 complications and stayed in hospital for $10.0 \pm 0.1$ days after surgery. They were only $75.3 \pm 14.0 \%$ satisfied with the treatment. 
So patients with optimistic not realistic attitudes towards forthcoming heart surgery have few complications, but stay for a long period in hospital after surgery.

Patients with optimistic-realistic attitudes towards forthcoming heart surgery have almost no complications, and the shortest stay in hospital.

\section{Discussion}

The situation of open heart surgery is very stressful for both body and mind. Patients experience uncertainty, loss of control, life risk, and great pain. In this situation each patient forms a unique attitude towards the forthcoming heart surgery. We have ascertained that the type of attitude is associated with the outcomes of surgery.

Patients with pessimistic and indifferent attitudes do not believe that surgery can help them. They fixate on complications and negative aspects of the surgery. Such patients have a long and complicated postoperative period.

Optimistic-realistic patients, although their physical conditions do not differ from those of pessimistic and indifferent patients, have less complications and a shorter stay in hospital. This phenomenon can be explained by the placebo (nocebo) effect.

Optimistic but not realistic patients stay in hospital longer then optimistic-realistic patients and need more time to rehabilitate. This probably occurs because they waste energy keeping their worries and fears out of conscious reach and appearing to be carefree.

This study shows that psychological support of open heart surgery patients should include help in forming an appropriate, optimistic attitude towards forthcoming open heart surgery. Knowing the type of the attitude towards forthcoming heart surgery can help a psychologist to identify a clear target.

We encourage further studies to determine whether interventions that target inadequate attitudes towards forthcoming open heart surgery can help to reduce the risk of postsurgical complications and long stays in hospital.

\section{References}

Allen, J. Becker, D. (1990). Factors related to functional status after coronary artery bypass surgery. Heart Lung, 19, 337-343.

Appels, A., Mulder, P. (1988). Excess fatigue as a precursor of myocardial infarction. European Heart J., 9, 768-764. doi: 10.1093/eurheartj/9.7.758

Atrinian, N. (1991). Stress experience of spouses of patients having coronary artery bypass during hospitalization and 6 weeks after discharge. Heart lung, 20, 52-59.

Berron, K. (1986). Transplant patient's perceptions about effective preoperative teaching. J Heart transplant, 5, 162-165.

Blumental, J.A., Lett, H.S. (2003). Depression as a risk factor for mortality after coronary artery bypass surgery. The Lancet, 352(9384), 604-609. doi: 10.1016/S0140-6736(03)14190-6

Blumenthal, J., Emery, C. (1988). The effects of exercise training on psychosocial functioning after myocardial infarction. J. Cardiopulm Rehabil., 8, 183-193. doi: 10.1097/00008483198805000-00003 
Bokeria, L.A. (2010). The influence of inherent heart disease on postoperative complications and mortality. Bulletin of Bakoulev CCVS RAMS for Cardiovascular Surgery, 11(5), 21-28.

Brummett, B., Morey, M. (2009). Prospective study of associations among positive emotions and functional status in older patients with coronary artery disease. J Gerontol B Psychol Sci Soc Sci., 64B(4), 461-469. doi: 10.1093/geronb/gbp041

Connerney, I., Sloan, R.P. (2010). Depression is associated with increased mortality 10 years after coronary artery bypass surgery. Psychosomatic medicine, 72, 874-881. doi: 10.1097/ PSY.0b013e3181f65fc1

Contrada, R.J., Boulifard, D.A. (2008). Psychologocal factors in heart surgery. Health Psychology, 27, 309-319. doi: 10.1037/0278-6133.27.3.309

Cserep, Z., Dalog, P. (2010). Psychosocial factors and major adverse cardiac and cerebrovascular events after cardiac surgery. Interactive Cardiovascular and thoracic surgery, 32, 61-619.

Gallagher, R., McKinley, S. (2007). Stressors and anxiety in patients undergoing coronary artery bypass surgery. American journal of critical care, 16(3), 248-265.

Hoyer, J., Eifert, G.F. (2008). Heart-focused anxiety before and after cardiac surgery. Journal of Psychosomatic Research, 64, 291-297. doi: 10.1016/j.jpsychores.2007.09.009

Laurence, A., Savett (2002). The human side of medicine. Westport: Auburn house.

Pignay-Demaria, V., Ltsperance, F., Demaria, R.G., Frasure-Smith, N., L. Parrault, L.P. (2003). Depression and anxiety and outcome of coronary artery bypass. Annals of Thoracic Surgeons, 75, 314-321. doi: 10.1016/S0003-4975(02)04391-6

Pogosova, G.V. (1996). Psychological rehabilitation after coronary artery bypass surgery. Cardio$\log y, 7$.

Rozanski, A., Blumenthal,J.A., Kaplan, J. (1999). Impact of Psychological Factors on the Pathogenesis of Cardiovascular Disease and Implications for Therapy. American Heart Association. doi: 10.1016/j.jacc.2004.12.005

Rymaszewska, J., Kiejna,A. (2003). Depression and anxiety in coronary artery bypass grafting patients. Eur Psychiatry, 18(4), 155-160. doi: 10.1016/S0924-9338(03)00052-X

Sokolova, E.T. Nikolaeva, V.V. (1995). Osobennosti lichnosti pri pogranichnyh rasstrojstvah i somaticheskih zabolevanijah [Personal features of patients with borderline personality disorders and somatic illnesses]. Moscow: SvR-Argus.

Thostov, A. S. (2002). Psihologija telesnosti [The psychology of corporality]. Moscow: Smisl.

Viars, J. (2009). Anxiety and open heart surgery. MedSurg Nursing, 18(5):283-5, 291.

Zaitsev, V.P., Aivazyan, T.A., Pogosova, G.V. (1997). Role of psychological factors of CAD before coronary artery bypass surgery. Cardiology, 8, 29-30.

Received: 25 September 2013

Accepted: 01 November 2013

Available online: 15 December 2013 